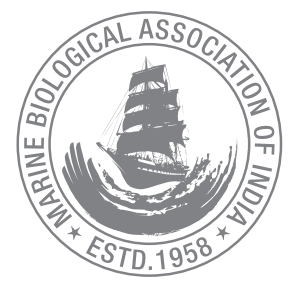

\title{
First report of cepheid scyphozoan jellyfish Marivagia stellata Galil \& Gershwin, 2010 from Palk Bay, southeast coast of India
}

\author{
R. Saravanan ${ }^{1 *}$, L. Ranjith ${ }^{2}$, P. Laxmilatha ${ }^{3}$, I. Syed Sadiq ${ }^{1}$ and K. K. Joshi ${ }^{4}$ \\ ${ }^{1}$ Regional Centre of ICAR-CMFRI, Mandapam Camp-623 520, Tamil Nadu, India. \\ ${ }^{2}$ Regional Station of ICAR-CMFRI, Tuticorin- 628001 , Tamil Nadu, India. \\ ${ }^{3}$ Regional Station of ICAR-CMFRI, Chennai-600 028, Tamil Nadu, India. \\ ${ }^{4}$ ICAR-Central Marine Fisheries Research Institute, Kochi-682 018, Kerala, India. \\ *Correspondence email: stingray_mr@yahoo.com
}

Received: 09 April 2020 Accepted: 22 Dec 2020 Published: 28 Dec 2020

\begin{abstract}
During a regular survey along the Palk Bay on $25^{\text {th }}$ July 2018, 16 specimens of Marivagia stellata were collected from shore-seine operations at Dhargavalasai in Ramanathapuram District of Tamil Nadu, southeast coast of India. The presence of $M$. stellata has been reported along the west coast earlier, however, this is the first time the occurrence of this species is reported along the Palk Bay coast of India. M. stellata is relatively a smaller jellyfish species and has been described only in 2010 from the Mediterranean coast of Israel. This species' sting is not harmful to human.
\end{abstract}

Keywords: Marivagia stellata, jellyfish, Palk Bay, Cepheidae

\section{Introduction}

The family Cepheidae consists of four genera and eight species. The Cepheid jellyfish Marivagia stellata has been first described in 2010 (Galil et al., 2010) when this species was collected from the Mediterranean coast of Israel. Indo-Pacific is considered as the hot-spot of Cepheid jellyfish (Galil et al., 2010). Marivagia differs from other Cepheid genera such as Cephea and Netrostoma by the absence of warts or knobs centrally on the exumbrella and filaments on oral disk and between mouths. Further, this species differ from Cotylorhiza as it lacks stalked suckers and filaments on the oral arms. This species was reported from Kerala coast only in 2013, though it is of Indian Ocean origin (Galil and Goren, 2013a; Galil et al., 2013).

\section{Material and methods}

During a regular survey along the Palk Bay on $25^{\text {th }}$ July 2018, 16 specimens of Marivagia stellata were collected from shore-seine operations at Dhargavalasai (Lat 9.326781 Lon $79.023664^{\circ}$ ) (Fig. 1), Ramanathapuram district, Tamil Nadu. The species was identified following Galil et al. (2010) (Fig. 2 \& 3). The sub umbrella canal structure was studied by injecting Alizarin red (Alexander, 1979). This is the first report of its occurrence along the east coast of India especially in Palk Bay. The specimens were in the bell diameter range of $5.16 \pm 0.38 \mathrm{~cm}$ and the weight range was observed to be $15.4 \pm 2.74 \mathrm{~g}$ respectively. 


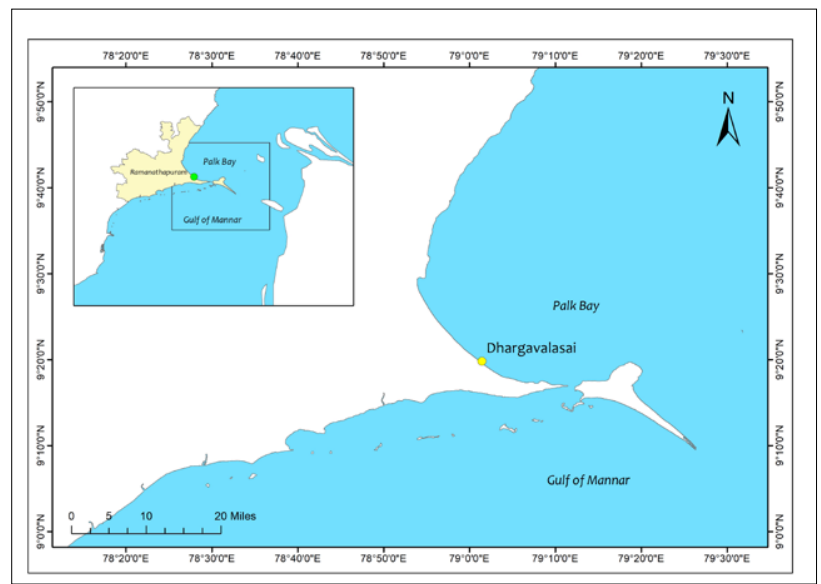

Fig. 1. Location of Collection of M. stellata in Palk Bay
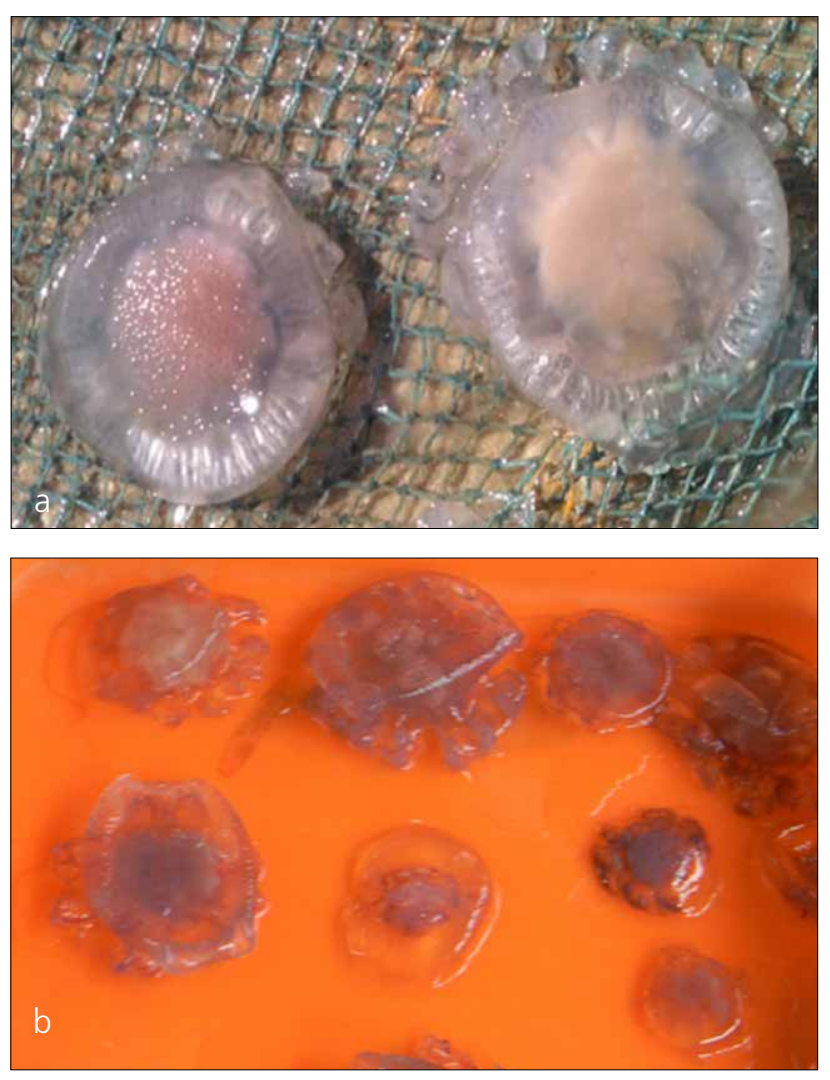

Fig. 2. (a \& b). Collection of M. stellata

\section{Results and discussion}

\section{Systematics}

Class : SCYPHOZOA Goette, 1887

Subclass : DISCOMEDUSAE Haeckel, 1880

Order : RHIZOSTOMEAE Cuvier, 1800

Family : CEPHEIDAE Agassiz, 1862

Genus : Marivagia Galil \& Gershwin, 2010

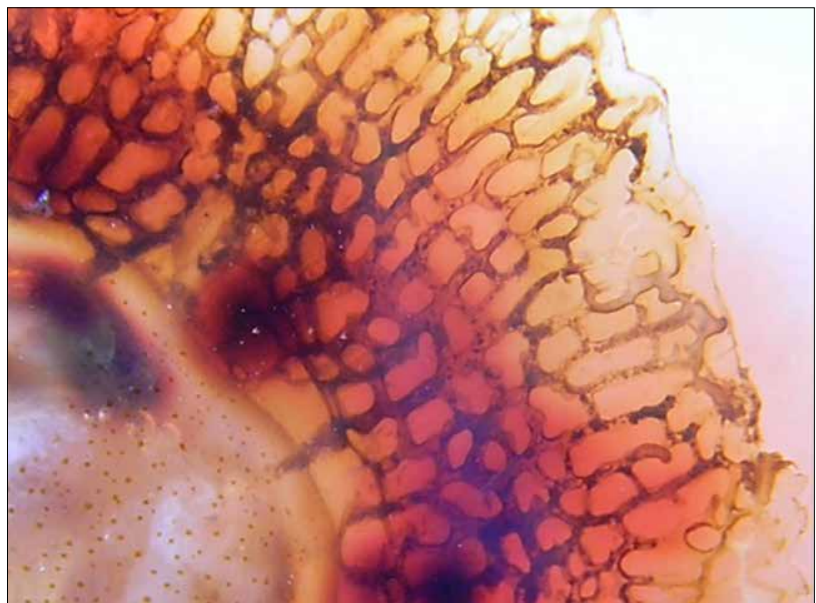

Fig. 3. Sub umbrella canal structure of $M$. stellata

Marivagia stellata Galil \& Gershwin, 2010

Members of the genera Cephea, Marivagia and Netrostoma have been reported from coastal waters of the west coast of India. However, the swarm of the Cepheid family is less noticeable along the east coast of India. The collection of 16 specimen of Marivagia stellata from Palk Bay coast of Dhargavalasai is the first report of its occurrence along the east coast of India. Marivagia stellata is considered to be an invasive species other than in its native range of the Indo-Pacific. Marivagia stellata is a translucent bluish-white jellyfish without a central dome, warts or knobs on the exumbrella surface but with a conspicuous pattern of reddish stars, dots and streaks clustered on the centre of the exumbrella. Sub-umbrella lacks filaments on oral disk and between mouths. The appearance of $M$. stellata in the Palk Bay coast indicate the presence of cryptic sessile, asexually reproducing polypoid stage, which can produce ephyra which grows into free swimming medusae.

In the Mediterranean Sea, M. stellata was recorded first from the Israel coast and it is the only species of the genus Marivagia (Galil et al., 2010). Gul et al. (2014) reported the occurrence of $M$. stellata along the Pakistan coast in the northern Arabian Sea. Recently, it has been reported along the Syrian coasts (Mamish et al., 2016) and in Lebanese waters (Bitar and Badreddine, 2019).

\section{Conclusion}

The Indo-Pacific species of Jellyfish M. stellata has been spotted for the first time along the Palk Bay coast during 2018. This indicates the presence of its polyps in the waters of Palk Bay. Monitoring of its bloom and its dispersal would help in understanding their swarming dynamics in these waters. 


\section{Acknowledgements}

We acknowledge Dr. A. Gopalakrishnan, Director, ICAR-Central Marine Fisheries Research Institute for facilities, support and encouragement.

\section{References}

Alexander, R. C. 1979. The Invertebrates, Cambridge University Press. 169 pp. Bitar, G. and Ali Badreddine. 2019. First record of Marivagia stellata Galil and Gershwin, 2010 (Scyphozoa: Rhizostomeae:Cepheidae) from the Lebanese waters in the eastern Mediterranean sea. J. Black Sea/Medit. Environ., 25(2):172-177.
Galil B. S. and M. Goren. 2013a. Metamorphoses: Bioinvasions in the Mediterranean Sea. In Goffredo S. and Dubinsky Z. (eds) The Mediterranean Sea: its history and present challenges. Dordrecht, The Netherlands: Springer Science + Business Media, p. 463-478.

Galil B. S., A. K. Biju, and J. R. Abdul. 2013. Marivagia stellata Galil and Gershwin, 2010 (Scyphozoa: Rhizostomeae: Cepheidae), found off the coast of Kerala, India. Biolnvasions Rec., 2: 317-318.

Galil B. S., L. A. Gershwin, J. Douek, and B. Rinkevich. 2010. Marivagia stellata gen. et sp. nov. (Scyphozoa: Rhizostomeae: Cepheidae), another alien jellyfish from the Mediterranean coast of Israel. Aquat. Invasions, 5:331-40.

Gul, S., M. Moazzam and B. S. Galil. 2014. Occurrence of Marivagia stellata (Scyphozoa: Rhizostomeae: Cepheidae) along the coast of Pakistan, northern Arabian Sea. Mar. Biodivers. Rec., 7(e112): 1-2.

Mamish, S., H. Durgham and M. S. Al-Masri. 2016. First record of the new alien sea jelly species Marivagia stellata Galil and Gershwin, 2010 off the Syrian coast. Mar. Biodivers. Rec., 9: 23. 